\title{
ANALISIS KEGIATAN PENAMBANGAN PASIR - BATU TERHADAP EROSI, KUALITAS AIR DAN SOSIAL EKONOMI MASYARAKAT DI SEKITAR SUNGAI INDRAGIRI
}

\author{
Tamrin, Zulfan Saam, Sofyan H. Siregar \\ Pascasarjana Ilmu Lingkungan Program Pascasarjana Universitas Riau, Pekanbaru, \\ e-mail : tamrin.lidyalfat@gmail.com
}

\begin{abstract}
The research was done in December 2016 to March 2017 and located in Pasir Keranji Village, Pasir Penyu Districts, Indragiri Hulu Regency. The purpose of this research is analizing the impacts of sandstone mining activities against erosion in Indragiri River, quality of Indragiri River water and local socio-economic conditions. Based on the reasearch, sand-stone mining in Indragiri River causes erosion so that the river body widened and the depth of the river is shallower due to sedimentation. Other than that, quality of Indragiri River water such as brightness, turbidity, TSS, DO and BOD 5 including the polluted category. This is caused by sand-stone mining activities, waste from palm factory and gold mining along the Indragiri River. Socially and economically, the sand-stone mining activities have a positive impact in improve the living standards of local communities and have a negative impact on environmental quality.
\end{abstract}

Keywords: Erosion, Indragiri River, Socio Economic, Water Quality.

\section{PENDAhuluan}

Faktor kependudukan yang bisa menghambat jalannya roda pembangunan antara lain: rendahnya tingkat pendidikan, jumlah penduduk yang tinggi tetapi tidak merata, kemiskinan dan keserakahan kelompok masyarakat tertentu diperparah lagi dengan wabah korupsi, kolusi, manipulasi dan nepotisme. Kondisi seperti itu berimbas kepada pemanfaatan sumber daya alam secara serampangan, sehingga terjadi pengrusakan sumber daya alam dan pencemaran lingkungan. Konsekuensi selanjutnya adalah terjadinya penurunan kualitas lingkungan, sehingga terjadilah ketidakseimbangan ekosistem dan rusaknya alam yang efek negatifnya akan kembali kepada masyarakat itu sendiri (Kartodihardjo, 2005).

Indonesia banyak memiliki perairan sungai dan komponen perairan yang menyertainya, saat ini terdapat 5950 DAS yang tercacat di Kementrian Lingkungan Hidup. Provinsi Riau juga tidak lepas dari permasalahan mengenai DAS, baik itu erosi ataupun pencemaran yang terjadi akibat aktivitas perusahaan, pembalakan sungai dan kandungan isinya untuk penambangan, pengerukan pasir dan pembangunan tempat tinggal yang tidak memperhatikan kelestarian dan daya dukung sungai itu sendiri.

Sungai Indragiri terbentang mulai dari wilayah perairan Lubuk Jambi Kabupaten Kuantan Singing sampai ke wilayah perairan Kabupaten Indragiri Hilir. Dampak aktivitas masyarakat dan perusahaan di perairan sungai Indragiri telah menimbulkan banyak masalah baik bagi ekosistem sungai itu sendiri, dan bagi masyarakat tempatan yang tinggal di sepanjang pinggiran sungai tersebut. Selain aktivitas perusahaan, di sepanjang aliran sungai berlangsung penambangan pasir dan penambangan emas tanpa izin yang telah 
menimbulkan terjadinya erosi tebing sungai. Kondisi demikian tentu tak dapat dibenarkan terus berlangsung karena berdampak pada kondisi ekonomi, sosial, dan lingkungan/kesehatan masyarakat.

Penambangan Pasir dan Batu tanpa izin di sepanjang Daerah Aliran Sungai (DAS) Indragiri menyebabkan masyarakat menjadi resah, karena aktivitas penambangan liar itu, banyak jalan yang menjadi rusak, bahkan dikhawatirkan terjadi penurunan kualitas tanah yang akan menyebabkan terjadinya erosi dan pendangkalan sungai (sedimentasi). Kegiatan penambangan ilegal ini marak terjadi di Desa Pasir Keranji, Desa Pasir Bongkal, Desa Tanjung Danau, dan Desa Pasir Batu Mandi. Penambangan Pasir dan Batu ilegal ini sangat berdampak buruk bagi infrastruktur yang berada di sekitar daerah tambang, terlebih dengan adanya aktivitas kendaraan berat membuat jembatan dan jalan menjadi rusak (Suleiman, 2013). Selain keruh, air sungai juga sudah tercemar oli karena aktivitas penambangan menggunakan mesin di sepanjang aliran sungai. Aktivitas penambangan yang berada di dekat masjid, sekolah maupun pemukiman warga lainnya dapat mengganggu karena mesin penambang membuat telinga warga menjadi pekak.

Oleh karena itu, perlu dilakukan penelitian mengenai dampak penambangan pasir - batu terhadap erosi pinggir Sungai Indragiri, kualitas air Sungai Indragiri dan kondisi sosial ekonomi masyarakat setempat.

\section{METODE PENELITIAN}

Penelitian ini telah dilaksanakan pada bulan Desember 2016 - Maret 2017 berlokasi di Desa Pasir Keranji Kecamatan Pasir Penyu Kabupaten Indragiri Hulu. Sampel kualitas air yang telah diambil, lalu dianalisis di
Laboratorium Produktivitas Perairan Universitas Riau untuk pengambilan data primer. Pengambilan data sekunder dilakukan di Kantor Kepala Desa Pasir Keranji, Dinas Kesehatan Kabupaten Inhu dan Kantor Camat Kecamatan Pasir Penyu.

Adapun alat dan bahan yang digunakan untuk menentukan kualitas air sungai dalam penelitian ini adalah termometer, secchi disk, filter, timbangan analitis, turbidimeter, pHmeter, DO meter dan tetrimeter dengan $\mathrm{Na}_{2} \mathrm{~S}_{2} \mathrm{O}_{3}$. Penentuan aspek sosial ekonomi digunakan bahan berupa data kuisioner dari para responden yaitu pekerja, masyarakat, pengelola tambang dan pejabat pemerintah. Alat lain yang digunakan yaitu GPS (Global Positioning System) untuk penentuan titik lokasi penelitian serta ice box untuk penyimpanan sampel sebelum dibawa ke laboratorium.

Penelitian ini menggunakan metode survei dengan melakukan pengukuran langsung di lapangan, pengujian di laboratorium dan wawancara di lokasi Penelitian ini termasuk pada penelitian kuantitatif karena data yang diperoleh berdasarkan hasil uji laboratorium.

Berdasarkan lokasi penambangan pasirbatu, maka dalam penelitian ini dilakukan pengukuran pada 4 titik stasiun yaitu:

Stasiun 1 = bagian hulu sungai \pm 50 meter sebelum areal penambangan (kontrol I).

Stasiun 2 = sekitar 20 meter dari Stasiun 1 (areal penambangan I).

Stasiun $3=$ sekitar 20 meter dari Stasiun 2 (areal penambangan II).

Stasiun $4=$ bagian hilir sungai \pm 50 meter setelah areal penambangan.

Pada penelitian ini dilakukan pengukuran beberapa parameter untuk mengukur kualitas air seperti suhu, kecerahan, kekeruhan, $\mathrm{pH}$, 
TSS, DO dan BOD5. Pengukuran masing masing parameter dilakukan sebanyak 3 kali pengulangan.

\section{a. Kecerahan}

Kecerahan air sungai diukur dengan menggunakan Secchi disk, dengan memasukkan alat tersebut ke dalam perairan sampai tidak terlihat lagi oleh kasat mata (jarak hilang) dan catat berapa jaraknya. Lalu Secchi disk ditarik secara perlahan hingga terlihat kembali (jarak tampak) dan dicatat jaraknya.

\section{b. Kekeruhan}

Sampel air sungai dimasukkan ke dalam gelas piala yang tersedia kemudian dibandingkan dengan standar air yang tersedia. Masukkan standar air yang telah dikocok dengan sampel air ke dalam turbidimeter kemudian distabilkan sesuai dengan standar hingga jarum turbidimeter menunjukkan angka standarnya. Setelah stabil, keluarkan standar tersebut lalu masukkan sampel air. Kemudian catat hasil yang ditunjukkan oleh jarum turbidimeter.

\section{c. TSS (Padatan Tersuspensi) Pengukuran TSS dilakukan dengan}

mengambil $50 \mathrm{~mL}$ sampel yang sudah dikocok merata. Lalu dimasukkan ke dalam alat penyaringan atau cawan Gooch yang sudah ada filter kertas di dalamnya. Kemudian disaring dengan pompa vakum. Filter kertas diambil dengan hati - hati, kemudian ditempatkan di atas cawan lalu dimasukkan ke dalam oven dan dipanaskan pada suhu 103 $105^{\circ} \mathrm{C}$ selama 1 jam. Lalu didinginkan dalam desikator dan ditimbang dengan cepat. Ulangi pemanasan dan penimbangan hingga beratnya konstan.

\section{d. DO (Oksigen Terlarut)}

Pengukuran DO dilakukan denganmetode titrasi yang berpatokan pada cara Wikler (Alaert dan Santika, 1984). Air sampel diambil dengan menggunakan botol tanpa terdapat gelembung udara di dalam botol, kemudian ditambahkan $1 \mathrm{~mL}$ mangan sulfat dan $1 \mathrm{~mL}$ larutan KI pekat hingga terbentuk endapan. Kemudian ditambahkan $2 \mathrm{~mL}$ asam sulfat dan dikocok hingga semua endapan hilang. Setelah itu larutan dipindahkan ke dalam Erlenmeyer dan dititrasi dengan larutan thiosulfat hingga berwarna kuning muda. Lalu teteskan 2-3 tetes indikator amilum hingga warna biru tua muncul. Selanjutnya larutan dititrasi dengan larutan thiosulfat hingga warna biru tua tersebut hilang. Jumlah titran yang terpakai dicatat.

\section{e. BOD5}

Sampel air yang telah diketahui kandungan oksigen terlarut (DO0) kemudian diinkubasi dalam botol BOD yang ditutupi aluminium foil pada suhu $20 \mathrm{oC}$ selama 5 hari. Pada hari kelima dilakukan pengukuran kandungan oksigen dengan menggunakan titrasi.

\section{HASIL DAN PEMBAHASAN}

Berdasarkan hasil pengamatan langsung dan wawancara pada responden diketahui bahwa kegiatan eksploitasi sungai berupa penambangan pasir - batu di sepanjang Sungai Indragiri menyebabkan terjadinya pendangkalan sungai yang ditandai dengan lebar badan sungai yang semakin lebar dan kedalaman sungai yang semakin dangkal. Akibatnya kemampuan sungai untuk menampung volume air semakin menurun dan pada musim penghujan volume air yang melebihi daya tampung sungai menyebabkan terjadinya bencana banjir.

Berdasarkan pengamatan, dapat diketahui bahwa terdapat kegiatan penambangan pasir batu di sepanjang Sungai Indragiri yang 
melintasi Desa Pasir Keranji. Sehingga perlu dilakukan pengukuran kualitas air untuk melihat dampak kegiatan penambangan pasir batu tersebut pada kualitas air Sungai Indragiri. Pengukuran masing - masing stasiun dilakukan sebanyak 3 kali pengulangan. Pada keempat stasiun dilakukan pengukuran kualitas perairan dengan beberapa parameter, baik secara fisika maupun kimia yaitu: suhu perairan, kecerahan, kekeruhan, kecepatan arus, pH (derajat keasaman), TSS (Total Suspended Solid), DO (oksigen terlarut) dan $\mathrm{BOD}_{5}$ (Biological Oxygen Demand).

Hasil pengukuran parameter kualitas perairan pada setiap stasiun lokasi penelitian disajikan pada Tabel 1.

Tabel 1. Kualitas Perairan pada Setiap Stasiun Penelitian

\begin{tabular}{lccccc}
\hline \multicolumn{1}{c}{ Parameter } & Stasiun 1 & Stasiun 2 & Stasiun 3 & Stasiun 4 & $\begin{array}{c}\text { Baku } \\
\text { Mutu* }\end{array}$ \\
Suhu $\left({ }^{\circ} \mathrm{C}\right)$ & 28,87 & 28,73 & 29,00 & 29,13 & Deviasi 3 \\
Kecerahan (cm) & 18,83 & 16,50 & 17,33 & 17,50 & - \\
Kekeruhan (NTU) & 87,00 & 90,00 & 94,33 & 94,33 & - \\
Kec. Arus (m/dtk) & 10,33 & 10,28 & 10,00 & 7,04 & - \\
TSS (mg/L) & 80,00 & 76,67 & 83,33 & 83,33 & 50,00 \\
DO (mg/L) & 2,02 & 1,74 & 1,63 & 1,84 & 4,00 \\
pH & 8,80 & 8,73 & 8,70 & 8,77 & $6-9$ \\
BOD5 (mg/L) & 0,54 & 0,26 & 0,17 & 0,29 & 3,00
\end{tabular}

Sumber : Data Primer, 2017

*Berdasarkan PP No. 82 Tahun 2001 Kelas II

Berdasarkan Tabel 1 diketahui bahwa suhu air Sungai Indragiri pada masing masing stasiun selama penelitian dilakukan cukup tinggi, yaitu berkisar antara $28,87^{\circ} \mathrm{C}$ $29,13^{\circ} \mathrm{C}$. Hal ini dikarenakan pengukuran suhu dilakukan saat musim kemarau sehingga kondisi lapangan cukup panas dari pukul 09.00 - 12.30 WIB. Selain itu, lokasi pengukuran merupakan kawasan terbuka sehingga permukaan air sungai langsung terkena sinar matahari. Suhu air pada masing - masing stasiun tidak berbeda secara signifikan, hal ini dikarenakan air sungai merupakan perairan

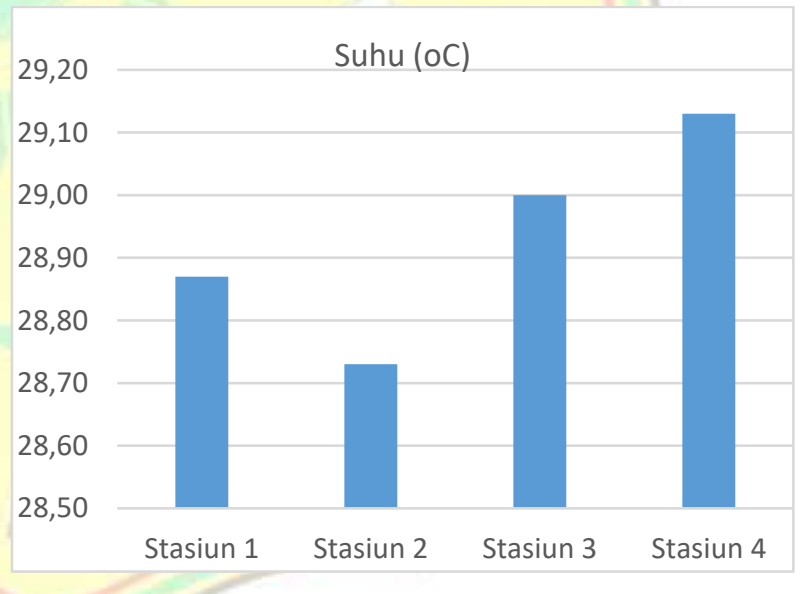

Gambar 1. Suhu Air pada Setiap Stasiun (Data Primer, 2017) yang mengalir (lotic water) sehingga pengadukan air terjadi setiap waktu. Suhu air Sungai Indragiri pada setiap stasiun dapat dilihat pada Gambar 1 berikut ini. 


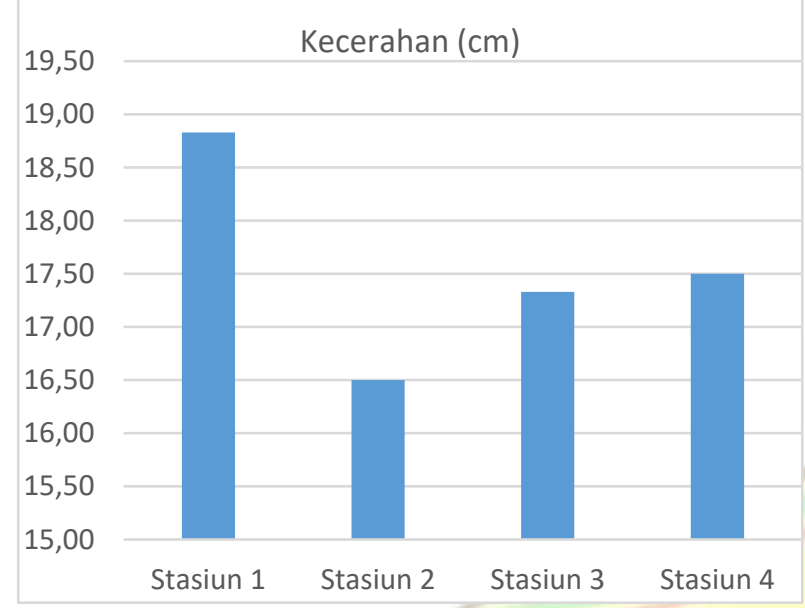

Gambar 2. Nilai Kecerahan Air pada Setiap Stasiun (Data Primer, 2017)

Berdasarkan Tabel 1 dan Gambar 2 diketahui bahwa Stasiun 1 memiliki nilai kecerahan paling tinggi yaitu 0,188 meter karena terletak di hulu sungai yang tidak terdapat aktivitas tambang pasir dan batu. Stasiun 2 memiliki nilai kecerahan paling rendah yaitu 0,165 meter karena merupakan lokasi aktivitas penambangan pasir - batu. Stasiun 2 dan Stasiun 3 merupakan titik lokasi aktivitas penambangan pasir batu, namun Stasiun 3 masih lebih tinggi nilai kecerahannya dibandingkan Stasiun 2. Hal ini dikarenakan pada Stasiun 3 berada di dekat hilir sungai sehingga aliran air sungai menyebabkan pasir, kerikil dan lumpur terbawa arus.

Menurut Eko (2010), kekeruhan adalah intensitas kegelapan suatu perairan akibat partikel - partikel yang terlarut di dalamnya. Tingkat kekeruhan berbanding terbalik dengan tingkat kecerahan. Jika tingkat kecerahan rendah, maka tingkat kekeruhannya tinggi dan berlaku sebaliknya. Nilai kekeruhan air pada setiap stasiun dapat dilihat pada Gambar $\mathbf{3}$ berikut ini.

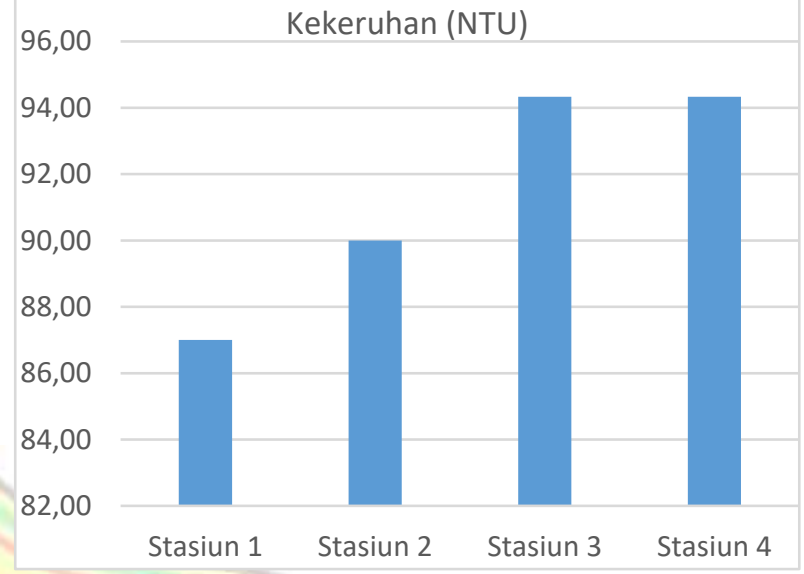

Gambar 3. Nilai Kekeruhan Air pada Setiap Stasiun (Data Primer, 2017)

Berdasarkan Tabel 1 dan Gambar 3 diketahui bahwa hasil pengukuran nilai kekeruhan di Sungai Indragiri yaitu berkisar antara 87,00 - 94,33 NTU. Tingginya nilai kekeruhan pada setiap stasiun disebabkan karena adanya bahan - bahan organik dan anorganik yang berasal dari limbah buangan domestik masyarakat dan aktivitas pertambangan pasir - batu. Warga setempat masih memiliki kebiasaan untuk membuang sampah ke selokan atau sungai. Hal ini juga bisa menjadi penyebab tingginya tingkat kekeruhan air Sungai Indragiri. Selain itu aktivitas penambangan pasir - batu juga dapat menyebabkan partikel pasir dan lumpur terangkat ke permukaan sungai sehingga air sungai menjadi keruh.

Menurut Chow (2009), kecepatan arus memegang peranan penting karena dapat mempengaruhi parameter lingkungan yang lain serta berperan dalam menentukan tingkat akumulasi bahan pencemar dalam perairan. Simatupang et. al. (2016) juga menyatakan bahwa kecepatan arus terbagi atas empat kategori, yaitu Kecepatan arus $<25 \mathrm{~cm} /$ detik = arus lambat; Kecepatan arus $25-50 \mathrm{~cm} /$ detik $=$ arus sedang; Kecepatan arus $50-100$ $\mathrm{cm} /$ detik $=$ arus cepat; Kecepatan arus $>100$ $\mathrm{cm} /$ detik $=$ arus sangat cepat 


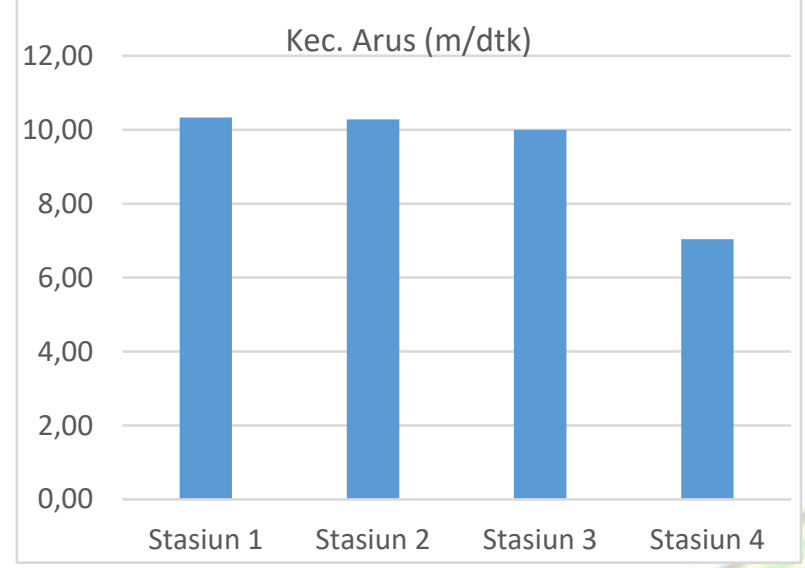

Gambar 4. Nilai Kecepatan Arus pada Setiap Stasiun (Data Primer, 2017)

Berdasarkan Tabel 1 dan Gambar 4 diketahui bahwa nilai kecepatan arus di sepanjang Sungai Indragiri yaitu berkisar antara 7,04 - 10,33 m/detik. Kecepatan arus tertinggi terdapat pada Stasiun 1 dan yang terendah pada Stasiun 4. Berdasarkan kategori Simatupang et. al. (2016), kecepatan arus perairan Sungai Indragiri termasuk perairan yang berarus cepat.

Total Suspended Solid (TSS) atau jumlah padatan tersuspensi merupakan parameter fisika yang berkaitan erat dengan kekeruhan. Semakin tinggi nilai kekeruhan, maka nilai kelarutan zat - zat yang tersuspensi juga akan semakin tinggi.

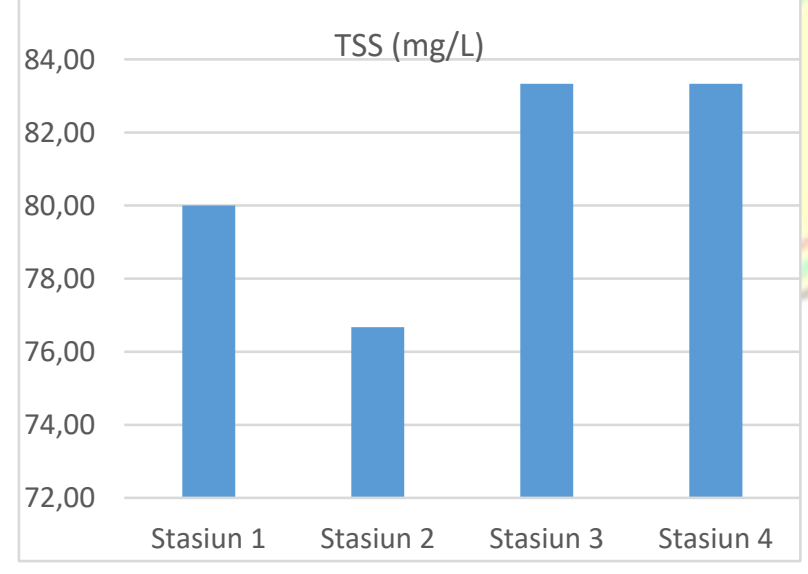

Gambar 5. Nilai TSS pada Setiap Stasiun (Data Primer, 2017)
Berdasarkan pada Tabel 1 dan Gambar 5 dapat diketahui bahwa nilai TSS pada setiap stasiun lokasi penelitian berkisar antara 76,67 - 83,33 mg/L. Jika dibandingkan dengan baku mutu dari PP No. 82 Tahun 2001 kelas II, hasil pengukuran nilai TSS pada perairan Sungai Indragiri telah melewati ambang batas dan termasuk golongan sedikit tercemar. Sehingga perairan sungai kurang memadai untuk mendukung kehidupan maupun perkembangbiakan organisme aquatik.

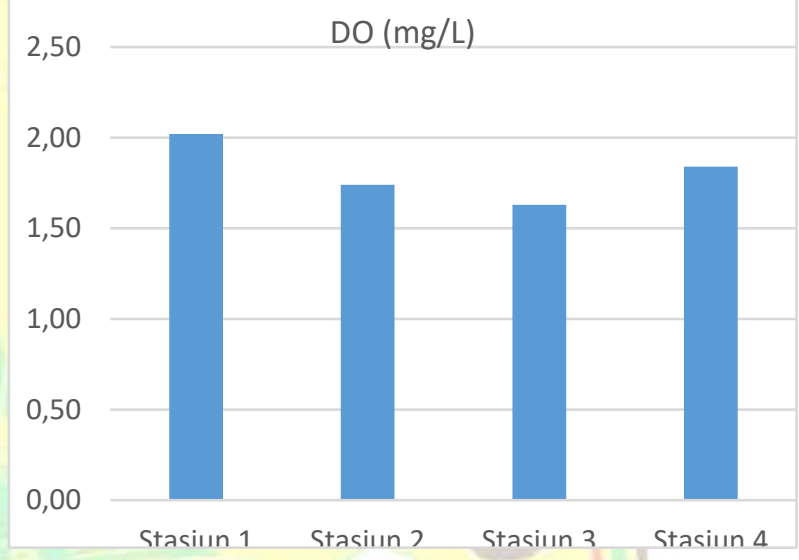

Gambar 6. Nilai Oksigen Terlarut (DO) pada Setiap Stasiun (Data Primer, 2017)

Berdasarkan pada Tabel 1 dan Gambar 6 diketahui bahwa nilai DO pada setiap stasiun lokasi penelitian berkisar antara 1,63-2,02 $\mathrm{mg} / \mathrm{L}$. Stasiun 1 memiliki nilai DO paling tinggi dan nilai DO paling rendah terdapat pada Stasiun 3. Menurut pendapat Eko (2010) dan PP no. 82 Tahun 2001 kelas II, nilai DO pada setiap stasiun di Sungai Indragiri berada di bawah batas minimal baku mutu. Hal ini menunjukkan bahwa kandungan oksigen terlarut dalam perairan sungai lokasi penelitian tidak memadai dan tidak mendukung kehidupan organisme aquatik di dalamnya, terutama ikan sungai.

Salah satu sifat kimia yang memengaruhi pertumbuhan tumbuhan dan hewan air (organisme aquatik) dan paling sering digunakan sebagai indikator kualitas air 
sebagai lingkungan hidup adalah derajat keasaman $(\mathrm{pH})$.

Derajat keasaman perairan dapat mempengaruhi daya tahan organisme aquatik, seperti $\mathrm{pH}$ yang rendah akan menyebabkan penyerapan oksigen akan terganggu.

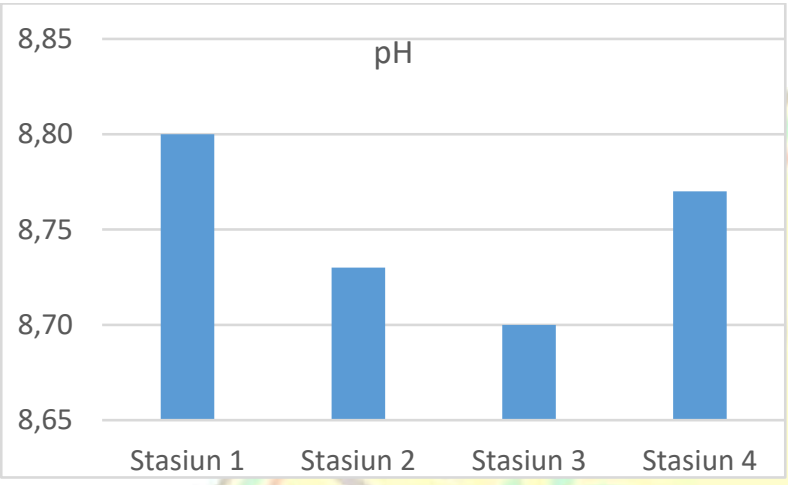

Gambar 7. Nilai pH pada Setiap Stasiun (Data Primer, 2017)

Berdasarkan Tabel 1 dan Gambar 7 diketahui bahwa nilai $\mathrm{pH}$ air sungai di lokasi penelitian setiap stasiun berkisar antara 8,708,80. Menurut Kordi dan Tancung (2009), kisaran $\mathrm{pH}$ yang sesuai untuk kehidupan organisme aquatik adalah 6,5-9. Selain itu, menurut PP No. 82 Tahun 2001 pH yang sesuai dalam kriteria baku mutu air kelas II adalah 6 - 9. Jadi berdasarkan tetapan tersebut, maka nilai $\mathrm{pH}$ pada setiap stasiun penelitian tidak melewati ambang batas minimum dan maksimum. Sehingga dapat dikatakan bahwa aktivitas penambangan pasir - batu tidak memberikan dampak negatif terhadap $\mathrm{pH}$ perairan Sungai Indragiri. Menurut Wibisono (2005), kebutuhan oksigen biokimia (BOD5) merupakan ukuran jumlah oksigen yang dibutuhkan oleh mikroorganisme untuk menguraikan hampir semua senyawa organik yang tersuspensi dalam air selama 5 hari.

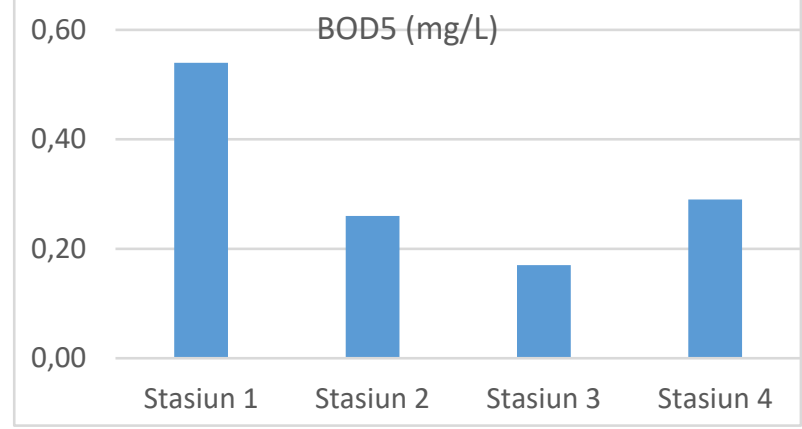

Gambar 8. Nilai BOD5 pada Setiap Stasiun (Data Primer, 2017)

Berdasarkan Tabel 1 dan Gambar 8 diketahui bahwa nilai BOD $_{5}$ pada setiap stasiun berkisar antara $0,17-0,54 \mathrm{mg} / \mathrm{L}$. Rendahnya nilai $\mathrm{BOD}_{5}$ dikarenakan minimnya bahan organik yang dapat diurai oleh mikroorganisme dalam proses dekomposisi. Partikel anorganik seperti pasir dan lumpur dalam perairan menyebabkan aktivitas mikroorganisme dalam air menjadi terganggu.

Berdasarkan wawancara dengan responden yang terdiri dari tokoh masyarakat/ warga setempat (60 orang), buruh/ pekerja tambang (40 orang), pemerintah desa (9 orang) dan pengelola tambang ( 2 orang) diketahui bahwa kegiatan penambangan pasir - batu di Desa Pasir Keranji memberikan dampak positif dan juga negatif terhadap sosial ekonomi masyarakat setempat. Dampak positif yang dirasakan masyarakat

\section{KESIMPULAN DAN SARAN}

Berdasarkan penelitian yang telah dilakukan, dapat disimpulkan bahwa penambangan pasir - batu di Desa Pasir Keranji menyebabkan badan sungai semakin melebar akibat erosi dan kedalaman sungai semakin dangkal akibat pengendapan. Selain itu, kegiatan penambangan pasir - batu memberikan dampak negatif pada beberapa kualitas air 
sungai (kecerahan, kekeruhan, TSS, DO dan $\mathrm{BOD}_{5}$ ) yang menyebabkan terjadinya pencemaran air sungai. Secara sosial dan ekonomi, kegiatan penambangan pasir batu memberikan dampak positif pada masyarakat, yaitu membuka lapangan kerja baru dan meningkatkan pendapatan masyarakat setempat. Sedangkan dampak setempat dengan adanya kegiatan penambangan ini adalah membuka lapangan kerja baru dan tingkat perekonomian masyarakat setempat semakin meningkat. Sedangkan dampak negatifnya adalah ketidaknyamanan masyarakat setempat akibat timbulnya polusi, rusaknya akses atau jalan di daerah setempat, pelebaran badan sungai/ pendangkalan sungai, dan jumlah ikan sungai semakin menurun. negatif kegiatan ini pada sosial ekonomi masyarakat, yaitu masyarakat menjadi tidak nyaman akibat adanya polusi, rusaknya jalan desa, pendangkalan sungai yang mengakibatkan banjir dan jumlah tangkapan ikan sungai semakin menurun.

Rekomendasi peneliti untuk masalah ini adalah perlu dilakukan peninjauan ulang tentang perizinan penambangan di sepanjang sungai oleh pemerintahan setempat. Harus dilakukan tindakan tegas bagi pelaku eksploitasi sungai yang tidak memiliki izin (ilegal) dan perlu dilakukan kajian mendalam tentang upaya pengelolaan lingkungan yang efektif dan efisien untuk mengatasi kerusakan perairan di Sungai Indragiri.

\section{DAFTAR PUSTAKA}

Chow, V. T. 2009. Open-Channel Hydraulics. The Blackburn Press. New York.

Eko, H. 2010. Evaluasi Kemampuan Pulih Diri Oksigen Terlarut Air Sungai Citarum Hulu. Jurnal Limnotek. 1 (17) : $17-36$.

Kartodihardjo, H. 2005. Di Bawah Satu Payung: Pengelolaan Sumber Daya Alam. Penerbit Suara Bebas. Jakarta.

Kordi, M. G. H. dan Tancung, A. B. 2009. Pengelolaan Kualitas Air dalam Budidaya Perairan. Rineka Cipta. Jakarta.

Simatupang, C.M.; Surbakti, H. dan Agussalim, A. 2016. Analisis Data Arus di Perairan Muara Sungai Banyuasin Provinsi Sumatera Selatan. Maspari Journal. 8 (1) : 15 -24 .

Suleiman. 2013.Tindak Tegas

Penambangan Liar di Inhu. http://www.riau24.com/Tindak_Te gas_Penambangan_Liar_di Inhu.

Wibisono, M. S. 2005. Pengantar Ilmu Kelautan. PT Grasindo anggota IKAPI. Jakarta 